\title{
Investigação psicanalítica dos determinantes psíquicos do consumo abusivo de substâncias psicoativas
}

Cláudia Henschel de Lima*

$O$ artigo examina a relevância da psicanálise para a determinação do diagnóstico diferencial e para a direção de tratamento de usuários de substâncias psicoativas. Sustenta-se que o desencadeamento do consumo abusivo de substâncias depende de fatores estruturais: 1. na psicose, recurso à droga como variável dependente da foraclusão do Nome-do-Pai; 2. na neurose, recurso à droga como variável dependente da baixa operatividade do Nome-do-Pai.

Palavras-chave: Adição, diagnóstico diferencial, direção de tratamento, psicanálise

*Universidade Federal Fluminense - UFF (Volta Redonda, RJ, Br) 


\section{Do higienismo aos determinantes psíquicos}

O objetivo do presente artigo é examinar a relevância da psicanálise para a determinação do diagnóstico diferencial e a direção de tratamento no contexto do problema do consumo abusivo de substâncias psicoativas e da orientação higienista para sua solução por parte do poder público no Brasil. Espera-se, assim, avançar na formulação de uma abordagem clínico-conceitual do problema cujo fio condutor seja fornecido pelos conceitos fundamentais da psicanálise.

No ano de 2004, o relatório A Política do Ministério da Saúde para a Atenção Integral a Usuários de Álcool e Outras Drogas, já alertava que o consumo abusivo de substâncias psicoativas (álcool e outras drogas) representava um grave problema de saúde pública, encontrando ressonância nos diversos segmentos da sociedade pela correlação comprovada entre o consumo e indicadores sociais de defasagem escolar, baixo nível socioeconômico e rotina de violência evidenciando o quanto tais indicadores derramam seus efeitos sobre o funcionamento subjetivo. Tomando como referência o crack, o problema ganha uma dimensão higienista. Além de seu consumo estar bastante identificado à população de crianças e jovens em situação de rua, o crack tornou-se o eixo central da temática nacional sobre o consumo de substâncias psicoativas e o termo epidemia vem sendo problematicamente empregado para explicar tanto a proliferação de cracolândias nos grandes centros urbanos como para justificar a formulação de uma política pública específica de enfrentamento do problema concentrada no abrigamento compulsório, a favor da manutenção da ordem pública e absolutamente distante da consideração das variáveis psíquicas em jogo no problema (CRM, 2012). Tal formulação verifica, ainda, a aliança entre uma psiquiatria biológica, que pensa a causalidade do consumo abusivo de substâncias psicoativas a partir do modelo neurofisiológico e um procedimento terapêutico sem controle que mistura dois tipos de prescrição, historicamente vinculados ao modelo manicomial, para o 
tratamento da adição: prescrição medicamentosa de Haldol e tratamento moral por meio do isolamento social (Henschel de Lima, Duarte Morais \& Nishimura, 2012).

Essas considerações indicam que o procedimento higienista toma a gravidade e extensão do problema do consumo abusivo de substâncias a partir exclusivamente do valor patológico da substância, refletindo a afirmação de Laurent (1998) de que a preocupação com a saúde mental, nestes casos, está orientada exclusivamente pela "saúde" em detrimento do "mental". Diante desse contexto, o artigo objetiva avançar na formulação de uma abordagem psicanalítica do problema, interrogando o desencadeamento do consumo abusivo de substâncias a partir das condições psíquicas do desencadeamento e em articulação com o funcionamento da estrutura psíquica.

Um estudo conduzido no campo psicanalítico por Alberti, Inem e Rangel (2003) levanta observações importantes sobre o consumo de substâncias a partir da estrutura. As autoras afirmam que alguns sujeitos, apesar de fazerem uso regular de uma substância psicoativa por vários anos, não se consideram adictos, pelo fato desta não ocupar lugar preponderante em suas vidas, não verificando as características do DSM-IV para o diagnóstico de Transtorno por Uso de Substâncias. Por outro lado, citam a ocorrência de casos em que os sujeitos consomem substâncias psicoativas com a mesma frequência e ao longo de período similar de tempo e que se consideram adictos pela ação devastadora da substância em suas vidas.

Outras referências aprofundam ainda mais a pesquisa sobre consumo abusivo de substâncias: o estudo de caso, publicado recentemente por Abello (2009) sobre toxidade pela água em um paciente que sofrera uma cirurgia renal indicando a relevância da toxidade no recurso ao objeto e não a natureza da substância; as considerações clínico-conceituais de Naparstek (2009) sobre o recurso à substância no quadro investigativo das alucinações na psicose. Ambos os estudos evidenciam a extensão do problema do consumo abusivo de substâncias para além da explicação neurofísiológica pelo efeito químico das substâncias psicoativas e em íntima conexão com quadros de desestabilização no funcionamento psíquico e invasão pulsional. Sendo assim, a investigação sobre a relação entre consumo de substâncias e estrutura psíquica, se converte no eixo central da psicanálise definindo os critérios de distinção entre os usuários e as modalidades de uso a partir das condições subjetivas de seu desencadeamento, bem como a elaboração de uma direção de tratamento a partir do diagnóstico diferencial entre neurose e psicose.

\section{Psicanálise e diagnóstico estrutural da adição}

O artigo sistematizará algumas referências centrais a respeito da causalidade do consumo abusivo de substâncias, presentes em Freud e em Lacan em torno do que, aqui, 
denominar-se-á de "Hipótese de Freud sobre a causalidade da adição" e "Hipótese de Lacan sobre a causalidade da adição". Essa sistematização será construída a partir de dois eixos centrais: a Carta 79 (Freud, 1897/1976), em que Freud define a masturbação como adição primária, e a Intervenção no Encerramento da Jornada de Cartéis na Escola Freudiana de Paris (Lacan, 1975), onde Lacan aborda a função da droga a partir da análise do estatuto da fobia como solução para a angústia. A organização dessas referências e seu exame mais detido cumpre a função de situar a relevância da pesquisa sobre a função da substância no funcionamento da estrutura psíquica, para o diagnóstico e a direção de tratamento do consumo abusivo de substâncias.

\section{A hipótese de Freud sobre a causalidade da adição}

No quadro do desenvolvimento epistemológico do conceito de pulsão e de sua relação com o inconsciente, o problema clínico que se coloca é: por que um sujeito recorre à substância psicoativa e não a um sintoma?

Na primeira referência, a Carta 79 (1897/1976), Freud formula o caráter tóxico da pulsão e é explícito com relação ao estatuto da adição. A partir do comentário de um caso clínico de histeria dissociativa, o autor sustenta a presença da pulsão sexual na base das adições, como a dipsomania, a paixão pelo jogo e a morfinomania. Nessa perspectiva, Freud propõe que as adições seriam formações de substituição em relação à adição primária, em relação à masturbação: “(...) somente como sucedâneo e substituto dela que outros vícios - álcool, morfina, tabaco adquirem existência." (Freud, 1896/1976, p. 323). Nesta passagem, fica evidente a referência uma lógica da constituição do psiquismo a partir da qual Freud hipotetizará sobre a casualidade da adição: como sucedâneo e substituto da masturbação. $\mathrm{O}$ entendimento da adição a partir dessa lógica ganha relevância a partir das ferramentas oferecidas pelo avanço na formulação dos três tempos da constituição do psiquismo verificado em "Fantasias histéricas e sua relação com a bissexualidade" (1908/1976), "Algumas observações gerais sobre ataques histéricos" (1909[1908]/1976) e "Os caminhos da formação dos sintomas" (1916-1917/1976). Ao longo desses textos, Freud estabelece a constituição lógica da estrutura psíquica, pela fantasia e a formação do sintoma, a partir do autoerotismo. Essa constituição lógica consiste, resumidamente, no seguinte processo:

Tempo 1: O ato masturbatório é um processo autoerótico que objetiva a obtenção de prazer de uma determinada zona erógena.

Tempo 2: Ação do recalcamento.

Tempo 3: O autoerotismo se funde à fantasia/formação do sintoma.

Freud sustenta que, no tempo 1, a masturbação não está soldada à fantasia sendo uma atividade autoerótica; apenas no tempo 3, após a ação do recalcamento, 
ocorre a fusão do autoerotismo à fantasia e à formação do sintoma. Partindo, então, da formulação inicial e relendo-a a partir da constituição lógica da estrutura da neurose, tem-se o aprofundamento da hipótese sobre a adição desenvolvida na Carta 79: ela tem o estatuto de formação substitutiva no ponto em que, na formação da estrutura psíquica, não se verifica a formação da fantasia e do sintoma que lhe é correlato. O que significa: 1 . situar a masturbação e o sintoma como respostas estruturalmente distintas; 2. equacionar adição e autoerotismo.

Essas formulações ganham complexidade com o texto "Contribuições a um debate sobre a masturbação" (1912/1976), no qual Freud sustentara a distinção diagnóstica entre psiconeuroses e neuroses atuais, definindo a etiologia do sintoma nas neuroses atuais como tóxica destituída de significação psíquica, de referência ao infantil e de recurso à fantasia. Da leitura desse texto é possível extrair a gênese tóxica do sintoma nas neuroses atuais e, consequentemente, uma analogia à adição. É em "Luto e melancolia" (1917/1976) que Freud efetivamente sustentará a correlação entre toxidade e supressão do dispêndio subjetivo com o recalque permitindo o aprofundamento da discussão clínica sobre diagnóstico diferencial para o desencadeamento do consumo abusivo de substâncias psicoativas no campo das neuroses. A reformulação da teoria das pulsões, a partir de 1920, com a elaboração do conceito de pulsão de morte, permitirá fundamentar a toxidade da pulsão. No texto "Dostoiévski e o parricídio" (1927/1976), Freud analisa a mania de jogo em Dostoiévski, sustentando sua causalidade na eclosão de um sentimento de culpa severo, tóxico:

(...) tinha assumido forma tangível como se fosse um ônus de dívidas, e ele pôde refugiar-se no pretexto de estar tentando, com seus ganhos nas mesas de jogo, possibilitar a volta à Rússia sem ser preso pelos credores. (...) Sabia que o importante era o jogo pelo amor ao jogo (...). Para ele, o jogo era também um método de autopunição (...). Todos os pormenores de sua conduta impulsivamente irracional demonstram isso (...). Quando suas perdas os reduziam à mais extrema necessidade, extraía disso uma segunda satisfação patológica. Podia então censurar-se e humilhar-se (...) (Freud, p. 219-220)

Neste sentido, o texto "O mal-estar na civilização" (1930[1929]/1976) confere precisão à elaboração clínico-conceitual sobre o recurso à substância desenvolvido até então. $\mathrm{O}$ autor localiza a intoxicação como amortecedor de preocupações, a medida paliativa mais eficaz para lidar com as decepções da vida. Relendo o conjunto das referências anteriores à luz do conceito de pulsão de morte, é possível depreender que o tratamento do consumo abusivo de substâncias depende da consideração sobre o modo como a substância atua na economia psíquica: é uma resposta aos impasses próprios da relação entre o sujeito e os ideais civilizatórios em que se verifica a formação de uma parceria fixa com a substância química. 


\section{A hipótese de Lacan sobre a causalidade da adição}

Com o objetivo de avançar nos fundamentos da hipótese lacaniana, recorrer-se-á ao momento em que Freud localiza a soldadura entre autoerotismo e fantasia articulando-o à definição de "falo", formulada por Lacan (1975-1976/2007) em O Seminário. Livro 23. O Sinthoma: "o falo é a conjunção do que chamei de esse parasita, ou seja, o pedacinho de pau em questão com a função da fala" (p. 16). Com essa definição, Lacan mostra que a inserção do falo depende da relação entre o órgão e a palavra. Tomando como referência os três tempos da constituição da estrutura psíquica em Freud e relendo-os à luz da definição de falo, ter-se-ia:

Tempo 1: Autoerotismo / Pênis-Órgão.

Tempo 2: Recalcamento /Ação da palavra.

Tempo 3: Fusão do autoerotismo à fantasia / Inscrição do falo.

A hipótese de Lacan sobre o recurso à droga pode ser lida a partir dessa temporalidade. De fato, em 1975, na Intervenção no Encerramento da Jornada de Cartéis na Escola Freudiana de Paris, o autor retoma a experiência de angústia de Hans que havia comentado por ocasião do seminário sobre a relação de objeto (Lacan, 1955-1956/1998), demonstrando que a formação da fobia é uma tentativa de solução para a angústia decorrente da eclosão do gozo em seu órgão distinta do sintoma. Lacan (1975) ressalta, ainda, o trabalho psíquico de Hans para lidar com a invasão da pulsão em seu órgão (falo) e a localiza como a porta de entrada na neurose, como o marco a partir do qual se estruturará a fantasia. No quadro desta discussão clínica sobre a distinção entre fobia e sintoma, Lacan formula, então, a hipótese referente ao estatuto da droga no funcionamento psíquico, condensando a pesquisa de Freud a respeito da fixação na satisfação autoerótica, ao localizar seu recurso no ponto em que se verifica a ruptura com o gozo fálico: “(...) il n’y a aucune autre définition de la drogue que celle-ci; c'est ce qui permet de rompre Le mariage avec le petiti-pipi" (Lacan, 1975, p. 113).

A hipótese de Lacan aprofunda o campo da pesquisa freudiana acerca do funcionamento da estrutura subjetiva estendendo-o da fantasia à pulsão, afirmando que o recurso à substância permitiria um curto-circuito do gozo fálico e, consequentemente, uma economia para o sujeito dos possíveis impasses referentes à sua eclosão. Sendo assim, ao sustentar que o recurso à droga incide no ponto em que ocorre a invasão da pulsão no corpo, Lacan aprofunda a elucidação do desencadeamento do consumo abusivo de substâncias psicoativas a partir do diagnóstico diferencial entre neurose e psicose. Nas neuroses, a hipótese sobre o recurso à substância, como ruptura com o gozo fálico, indica a possibilidade de ocorrência de uma suspensão conjuntural com o gozo fálico no campo das neuroses devido à fragilização da ação do Nome-do-Pai na regulação pulsional. Dessa forma, articulando as formulações de Freud e de Lacan, é possível sustentar que: 1. o recurso à droga 


\section{ARTIGOS}

evidencia o caráter tóxico do autoerotismo, pela predominância da satisfação mortífera da pulsão, destituída da regulação promovida pelo recalcamento e do retorno do recalcado; 2. a direção de tratamento visa localizar o ponto de defesa contra a pulsão e articula essa defesa ao modo de funcionamento psíquico, ou seja, ao campo da estrutura psíquica.

A hipótese de Lacan ganha complexidade quando é aplicada à direção de tratamento da psicose, já que a ruptura com o gozo fálico se instalou de antemão por meio da foraclusão do Nome-do-Pai. Sendo assim, a interrogação diagnóstica para os casos de adição, a partir das referências de Freud e Lacan, é em torno do estatuto da ruptura com a significação fálica: seria ela uma resposta à fragilização da ação do Nome-do-Pai sobre a pulsão que ocorre em alguns casos onde a defesa impera ou estaria ela articulada diretamente à foraclusão do Nome-do-Pai?

Algumas indicações podem ser encontradas nos estudos de caso em adição, extraídos da literatura psicanalítica nacional. No primeiro, Calmon (2010) examina um caso de adição que revela que a intoxicação surge como resultado de uma supressão do dispêndio psíquico causada pelo relaxamento das pressões do recalcamento. Para a autora o caso evidencia o uso da droga como formação substitutiva, intimamente associada a uma defesa contra a pulsão. Em um segundo estudo de caso, Henschel de Lima, Lipiani et al. (2012) desenvolvem a hipótese de que o recurso à droga pode obedecer à lógica subjetiva de tratamento do real pelo real com impactos devastadores no imaginário. Para o caso de psicose em questão, a paciente recorria ao crack como tentativa desesperada de estabilização do fenômeno elementar, justificando sua ocorrência pelo uso abusivo da substância.

$\mathrm{Na}$ literatura científica internacional, destacam-se os estudos de caso de Naparstek (2009) e Aucremanne (2011). Aucremanne (2011) se refere à função de ruptura operada pela substância em casos em que o Outro advém sobre o sujeito seja sob a forma do excesso - nas versões do invasivo, ameaçador - seja sob a forma de um demasiado pouco, nas versões do deixar cair, da negligência. $\mathrm{O}$ autor, com isso, indica que a localização do Outro no caso clínico e o modo como a substância se localiza no quadro de suas versões podem oferecer alguma bússola para o diagnóstico de psicose. Em outro estudo de caso, Naparstek (2009) sustenta que a função da substância psicoativa em casos de psicose não produz, necessariamente, um excesso de gozo funcionando, ao contrário, para limitar o gozo no corpo indicando a importância do clínico localizar as circunstâncias de vida do paciente que desencadeiam a invasão pulsional e o recurso à substância. No entanto, o autor alerta para o fato de que esta solução deixa o sujeito no limite da passagem ao ato por representar um tratamento, um pharmakon da invasão pulsional no corpo, pelo recurso à substância, que produz colateralmente a mesma invasão pulsional. O que conduz a pensar que, nos casos de psicose, o recurso à substância seria um resultado direto da foraclusão do Nome-do-Pai. 


\section{Considerações finais}

O rigor clínico das hipóteses de Freud e de Lacan mostra que a efetividade da direção de tratamento desses casos depende da consideração do estatuto da substância no funcionamento da estrutura psíquica. De fato, tais hipóteses definem a ocorrência do recurso à substância no ponto em que não se verifica a formação do sintoma e dos efeitos da ação do Nome-do-Pai na formação da estrutura psíquica. Da mesma forma, a referência aos estudos de caso publicados em periódicos científicos elucida a ocorrência da toxidade da repetição pulsional nas recaídas, na retomada da demanda de ajuda e nas internações, bem como a tentativa de solucionar a invasão pulsional, permitindo sustentar a hipótese clínica de que o desencadeamento do consumo abusivo de substâncias depende de fatores estruturais assim localizados:

1) Na psicose: o recurso à substância psicoativa é uma variável dependente da foraclusão do Nome-do-Pai.

2) Na neurose: o recurso à substância é uma variável dependente da baixa operatividade do Nome-do-Pai.

Assim, diante da variedade da relação de cada sujeito com a substância psicoa46 tiva, torna-se necessário determinar o ponto de desestabilização sintomática da estrutura neurótica ou psicótica. O que indica a possibilidade de uma direção efetiva de tratamento orientada pelo diagnóstico de estrutura e não pelo valor patológico das substâncias psicoativas.

Agradeço a Elisabeth Henschel de Lima Costa a versão do resumo para a lingua alemã.

\section{Referências}

Abello, M. (2009). El Água Tóxica de Mario. In Naparstek, F (org.). Introducción a la clínica con toxicomanias y alcoholismo II (pp. 6-13). Buenos Aires: Grama Ediciones.

Alberti, S. et al. (2003, setembro). Fenômeno, estrutura, sintoma e clínica: a droga. Revista Latinoamericana de Psicopatologia Fundamental, São Paulo, 6(3), 11-29.

Aucremanne, J. L. (2011). Las Conversaciones del TyA. Pharmakon: Chifladuras Adictivas, Buenos Aires, 12, 61-66.

Brasil (2004). Ministério da Saúde. Secretaria Executiva. Secretaria de Atenção à Saúde. Coordenação Nacional DST/Aids. A Política do Ministério da Saúde para a Atenção Integral a Usuários de Álcool e outras Drogas. Brasília: Ministério da Saúde. 


\section{ARTIGOS}

Calmon, A. (2010, novembro/2011, abril). A droga ou a vida. aSEPHallus, Rio de Janeiro, 6(11), 86-97. Recuperado de <www.nucleosephora.com/asephallus>, em: 1 dezembro 2012.

Conselho Regional de Medicina do Estado de São Paulo. Câmara Técnica de Saúde Mental (2012, março). Cracolândia, por Diretrizes Convergentes. Revista Latinoamericana de Psicopatologia Fundamental, São Paulo, 15(1), 11-13

Freud, S. (1976). Carta 79. In Edição Standard Brasileira das Obras Psicológicas Completas de Sigmund Freud (v. I). Rio de Janeiro: Imago (Trabalho original publicado em 1897).

Freud, S. (1976). A sexualidade na etiologia das neuroses. In Edição Standard Brasileira das Obras Psicológicas Completas de Sigmund Freud (v. I). Rio de Janeiro: Imago (Trabalho original publicado em 1898).

Freud, S. (1976). Fantasias histéricas e sua relação com a bissexualidade. In Edição Standard Brasileira das Obras Psicológicas Completas de Sigmund Freud (v. IX). Rio de Janeiro: Imago (Trabalho original publicado em 1908).

Freud, S. (1976). Algumas observações gerais sobre ataques histéricos. In Edição Standard Brasileira das Obras Psicológicas Completas de Sigmund Freud (v. IX). Rio de Janeiro: Imago (Trabalho original publicado em 1909[1908]).

Freud, S. (1976). Contribuições a um debate sobre a masturbação. In Edição Standard Brasileira das Obras Psicológicas Completas de Sigmund Freud (v. XII). Rio de Janeiro: Imago (Trabalho original publicado em 1912).

Freud, S. (1976). Luto e melancolia. In Edição Standard Brasileira das Obras Psicológicas Completas de Sigmund Freud (v. XIV). (Trabalho original publicado em 1917).

Freud, S. (1976). Os caminhos da formação dos sintomas. In Edição Standard Brasileira das Obras Psicológicas Completas de Sigmund Freud (v. XVI). Rio de Janeiro: Imago (Trabalho original publicado em 1916-1917).

Freud, S. (1976). Dostoiévski e o parricídio. In Edição Standard Brasileira das Obras Psicológicas Completas de Sigmund Freud (v. XXI). Rio de Janeiro: Imago (Trabalho original publicado em 1928).

Freud, S. (1976). O mal-estar na civilização. In Edição Standard Brasileira das Obras Psicológicas Completas de Sigmund Freud (v. XXI). Rio de Janeiro: Imago (Trabalho original publicado em 1930[1929]).

Henschel de Lima, C., \& Lipiani, A. et al. (2012, março). O que pode a psicanálise diante do destino para o pior? Considerações sobre a direção de tratamento das toxicomanias no avesso do discurso do mestre contemporâneo. Opção Lacaniana online, Rio de Janeiro, 3(7). Recuperado de <http://www.opcaolacaniana.com. br/pdf/numero_7/que_pode_psicanalise_diante_do_destino_para_o_pior.pdf >, em 15 março 2013.

Henshcel de Lima, C., Duarte Morais, D., \& Nishimura, A.(2012). Quando a política pública para álcool e outras drogas, no Brasil, contraria o processo de inovação. Trabalho 
Completo publicado nos Anais do CASI 2012 - Congresso de Administração Sociedade e Inovação. Volta Redonda, Universidade Federal Fluminense.

Lacan, J. (1998). De uma questão preliminar a todo tratamento possível da psicose. In Escritos. Rio de Janeiro: Jorge Zahar (Trabalho original publicado em 19551956).

Lacan, J. (1995). O seminário. Livro 4. A relação de objeto. Rio de Janeiro: Jorge Zahar (Trabalho original publicado em 1956-1957).

Lacan, J. (1975). Intervenção no encerramento da Jornada de Cartéis na Escola Freudiana de Paris. Documentos para uma Escola. Rio de Janeiro, Publicação Interna da Escola da Letra Freudiana, v. 0.

Lacan, J. (2007). O seminário. Livro 23. O sinthoma. Rio de Janeiro: Jorge Zahar. (Trabalho original publicado em 1975-1976).

Laurent, E. (1998). Mental?. Pharmakon, Buenos Aires, 6-7, 87-90.

Malengreau, P. (2009). Clínica del toxicómano. Pharmakon: El Lazo Social Intoxicado, Buenos Aires, 11, 35-42.

Naparstek, F. (2009). La alucinación en la intoxicación y en la psicosis. Pharmakon: El Lazo Social Intoxicado, Buenos Aires, 11, 63-68.

\section{Resumos}

(Psychoanalytical research on the psychic determinants of substance abuse)

This article examines the importance of psychoanalysis for determining differential diagnoses and direction of treatment for users of psychoactive substances. It argues that the onset of the substance abuse depends on structural factors: 1. In psychosis, drug use as a dependent variable for foreclosure of the Name of the Father, 2. In neurosis, drug use as a dependent variable for low operability of the Name of the Father.

Key words: Addiction, differential diagnosis, direction of treatment, psychoanalysis

(Recherche psychanalytique sur les déterminants psychiques de l'abus de psychotropes)

Notre article examine la pertinence de la psychanalyse pour déterminer le diagnostic différentiel et pour orienter le traitement des toxicomanes. Nous soutenons que l'apparition de l'abus de psychotropes dépend de facteurs structurels: 1. dans la psychose, l'utilisation de drogues comme une variable dépendante de la forclusion du Nom du Père, 2. dans la névrose, l'utilisation de drogues comme une variable dépendante de l'opérativité réduite du Nom du Père.

Mot clés: Toxicomanie, diagnostic différentiel, orientation du traitement, psychanalyse 


\section{ARTIGOS}

(La investigación psicoanalítica de los determinantes psíquicos del abuso de sustancias psicoactivas)

El artículo examina la relevancia del psicoanálisis para determinar el diagnóstico diferencial así como para la dirección del tratamiento de los usuarios de substancias psicoactivas. Desde esta perspectiva teórica se sostiene que el inicio del abuso de substancias depende de factores estructurales: 1. en la psicosis, el uso de drogas como una variable dependiente de la forclusión del Nombre del Padre, 2. en la neurosis, el uso de drogas como una variable dependiente de la baja operatividad del Nombre del Padre.

Palabras claves: Adicción, diagnóstico diferencial, orientación del tratamiento, psicoanálisis

(Psychoanalytische Untersuchung psychischer Bestimmungsfaktoren für den übertriebenen Konsum psychoaktiver Substanzen)

Dieser Beitrag untersucht die Bedeutung der Psychoanalyse für die Bestimmung der Differentialdiagnose und zur Richtungsweisung einer Behandlung für Benutzer psychoaktiver Substanzen. Es wird davon ausgegangen, dass die übertriebene Einnahme der Substanzen in Abhängigkeit von strukturellen Faktoren ausgelöst wird: 1. In der Psychose ist der Zugriff auf Drogen eine Alternative, die von der Verwerfung des Namens-des-Vaters abhängt; 2. In der Neurose, ist der Zugriff auf Drogen eine Alternative, die vom schwachen Wirkungsgrad des Namens-des-Vaters abhängig ist.

Schlüsselwörter: Abhängigkeit, differenzierte Diagnose, Behandlungsrichtung, Psychoanalyse

Citação/Citation: Lima, C. H. de (2014, março). Investigação psicanalítica dos determinantes psíquicos do consumo abusivo de substâncias psicoativas. Revista Latinoamericana de Psicopatologia Fundamental, 17(1), 39-50.

Editor do artigo/Editor: Manoel Tosta Berlinck

Recebido/Received: 18.12.2012/12.18.2012 Aceito/Accepted: 12.3.2013/3.12.2013 
Copyright: (C) 2009 Associação Universitária de Pesquisa em Psicopatologia Fundamental/ University Association for Research in Fundamental Psychopathology. Este é um artigo de livre acesso, que permite uso irrestrito, distribuição e reprodução em qualquer meio, desde que o autor e a fonte sejam citados / This is an open-access article, which permits unrestricted use, distribution, and reproduction in any medium, provided the original authors and sources are credited.

Financiamento/Funding: A pesquisa é financiada pela Fundação de Amparo à Pesquisa do Estado do Rio de Janeiro - FAPERJ / The research is funded by the Fundação de Amparo à Pesquisa do Estado do Rio de Janeiro - FAPERJ.

Conflito de interesses/Conflict of interest: A autora declara que não há conflito de interesses / The author declares that has no conflict of interest.

\section{Cláudia Henschel de Lima}

Doutora em Psicologia Social e da Personalidade pelo Programa de Pós-Graduação em Psicologia da Universidade Federal do Rio de Janeiro - UFRJ (Rio de Janeiro, RJ, Br); Pós-doutoranda pelo Programa de Pós-Graduação em Psicanálise da Universidade do Estado do Rio de Janeiro - UERJ (Rio de Janeiro, RJ, Br); Professora Adjunta do Departamento de Psicologia. Universidade Federal Fluminense. Instituto de Ciências Humanas e Sociais. Volta Redonda; Coordenadora do Laboratório de Investigação das Psicopatologias Contemporâneas - LAPSICON (Volta Redonda, RJ, Br); Membro da Associação Universitária de Pesquisa em Psicopatologia Fundamental (São Paulo, SP, Br).

Universidade Federal Fluminense. Laboratório de Investigação das Psicopatologias Contemporâneas

Rua Desembargador Ellis Hermydio Figueira 783, bloco A, sala 309 - Aterrado

27213-415 Volta Redonda, RJ, Br

e-mail: claudiahlima@vm.uff.br 